\title{
Chromosome changes in Alzheimer's presenile dementia
}

\author{
K E BUCKTON,* L J WHALLEY, $\dagger$ M LEE,* AND J E CHRISTIE $\dagger$ \\ From * the MRC Clinical and Population Cytogenetics Unit, Western General Hospital; and \\ the MRC Brain Metabolism Unit, Thomas Clouston Clinic, Edinburgh.
}

SUMMARY Lymphocyte chromosomes were examined in 36 patients with Alzheimer's presenilea dementia, 36 healthy, age and sex matched controls, and 36 sex matched, non-demented, elderly 0 controls, approximately 20 years older than the Alzheimer patients. Increased chromosome aneu- $\overrightarrow{-}$ ploidy was found in females with Alzheimer's disease but not in male subjects. Chromosomeos abnormalities observed in female patients were similar to those observed in elderly controls, though음 in this latter group there was an increase in the frequency of cells that had lost an X chromosome.In the female Alzheimer patients and the elderly controls, there was an increase in the frequency of autosomal aneuploid cells but no single chromosome was preferentially affected. Because the chromosome abnormalities found in Alzheimer's disease are similar in nature but not as extensive as气 those observed in senescence in the absence of dementia, it is argued that chromosome aneuploidy $\rightarrow$ is more likely to be related to processes concerned with ageing rather than being specifically linkedo్ to the dementia of Alzheimer's disease.

Dementia is a major public health problem and affects about $5 \%$ of people over 65 years of age and $20 \%$ of those over 80 years. $^{12}$ The cause of the disease is unknown, but its incidence appears closely linked to the processes of ageing, since senile plaques, one of the characteristic neuropathological features of senile dementia, also occur in old age in the absence of dementia. ${ }^{3}$ Genetic factors may contribute to both ageing ${ }^{4}$ and to the pathogenesis of dementia. ${ }^{5}$ The neuropathological changes of Alzheimer's disease are also found in most patients with Down's syndrome dying after the age of 35 years, ${ }^{6}$ strengthening the view that genetic factors may make an important contribution to Alzheimer's disease.

The exact nature of possible genetic factors is unknown, but may be linked to other pathological changes observed in ageing. In particular, a number of careful studies have established that with ageing there is an increased number of aneuploid cells in which sex chromosomes are more often lost or gained than autosomes. ${ }^{7-10}$ Nielsen ${ }^{11}$ postulated that dementia and the chromosome changes of ageing may both be caused by misassembly of tubular protein, leading to the characteristic neurofibrillary tangles of Alzheimer's disease as well as faulty

Received for publication 21 May 1982. spindle formation, causing inexact chromosome⿳亠二口 segregation at cell division. So far, 10 cytogeneticő studies of both senile and presenile dementia of the Alzheimer type have been reported, yielding as yet inconclusive results, although a total of about 1733 patients has been examined. In most series the number of subjects studied has been too small to: allow satisfactory statistical analysis. Two studies ${ }^{12}{ }^{13}$ have reported chromosome abnormalities, but the majority of studies have found no abnormality eithero of karyotype or banding pattern. ${ }^{11}$ 14-20

This study set out to examine lymphocyte chromo-o somes from a large sample of patients with Alzheimer's presenile dementia. The aim was too distinguish any chromosome changes observed in presenile dementia from those associated witho ageing in the absence of dementia. In addition, because of the association between Down's syn? drome with trisomy of chromosome 21 and $\mathbb{O}$ Alzheimer's disease, we wished to know whether N among autosomes that might be lost or gainedo from cells in Alzheimer's presenile dementia chromosome 21 was preferentially affected in this condition.

\section{Materials and methods}

Patients with Alzheimer's presenile dementia were界 
identified among out-patients and in-patients of mental hospitals in south-east Scotland. Criteria were: gradual onset of memory loss before 65 years, absence of focal neurological signs or peripheral vascular disease, and no history of mental handicap or head injury or alcoholism or other possible cause of dementia. Thirty-six patients were identified and comprised 23 females aged between 42 and 79 years and 13 males aged between 53 and 69 years. Since the study was completed, six patients have died and the diagnosis of Alzheimer's disease has been confirmed at necropsy. Each patient was age and sex matched with a healthy control. A second group of non-demented 'senescent' controls were approximately 20 years older than the Alzheimer patients with whom they were matched for sex. The 'senescent' controls were all leading active, independent lives at home and at interview with a psychiatrist (LJW) appeared knowledgeable of current events, could recall a new name and address after 5 minutes, and had a satisfactory performance on the paired associate learning test and the digit span test.

Differences between the three matched samples were compared using Student's paired $t$ test. The frequencies of abnormalities were expressed as percentages of total cells counted for each subject and 'normalised' using the angular (arc-sine) transformation.
Chromosome studies were performed on whole blood cultures using the method described by Galloway and Buckton. ${ }^{10}$ An attempt was made to analyse 25 to 50 cells from two different cultures which had been incubated for 48 hours 'early' and 72 hours 'late', but this was not always possible. The cells from the Alzheimer patients, the healthy controls, and the 'senescent' controls were all treated similarly, but were not necessarily scored by the same investigator. All cells were counted and scanned for any abnormality and if an abnormality was suspected or the cell was aneuploid, a full analysis was carried out. Any cell which could have been broken when being spread on the slide was not included in the study, but as this was not always obvious, some of the aneuploid cells could have been technical artefacts.

\section{Results}

Loss of the $\mathrm{X}$ chromosome in females and the $\mathrm{Y}$ chromosome in males and precocious splitting of the $\mathrm{X}$ chromosome (ace $\mathrm{X}$ ) in both sexes is known to be a phenomenon associated with ageing and these categories of abnormality are presented separately in tables 1 and 2. 'Other chromosomal abnormality' refers to cells with an abnormal analysis and includes

TABLE 1 Results of chromosome studies in female patients with Alzheimer's presenile dementia, healthy controls, and 'senescent' controls.

\begin{tabular}{|c|c|c|c|c|c|c|}
\hline & \multicolumn{2}{|c|}{ Healthy controls } & \multicolumn{2}{|c|}{ Alzheimer patients } & \multicolumn{2}{|c|}{ 'Senescent' controls } \\
\hline & No & $\begin{array}{l}\% \\
(M e a n \pm S D)\end{array}$ & No & $\stackrel{\%}{(M e a n \pm S D)}$ & No & $\begin{array}{l}\% \\
(M e a n \pm S D)\end{array}$ \\
\hline Total cells & 2103 & 100 & 1107 & 100 & 1225 & 100 \\
\hline $46, N$ & $1948+$ & $92 \cdot 63 \pm 5 \cdot 93$ & 960 & $86 \cdot 72 \pm 6 \cdot 42$ & $1019^{*}$ & $83 \cdot 18 \pm 8 \cdot 04$ \\
\hline $45, X$ & 27 & $1 \cdot 28 \pm 1 \cdot 27$ & 28 & $2 \cdot 53 \pm 2 \cdot 63$ & 51 & $4 \cdot 16 \pm 4 \cdot 25$ \\
\hline $47, X X X$ & 9 & $0.42 \pm 0.99$ & 8 & $0.72 \pm 1.29$ & 15 & $1 \cdot 22 \pm 1 \cdot 89$ \\
\hline Ace $(X)$ & 42 & $2 \cdot 00 \pm 2 \cdot 06$ & 24 & $2 \cdot 16 \pm 1 \cdot 82$ & $54^{*}$ & $4 \cdot 41 \pm 4 \cdot 68$ \\
\hline Other non-modal cells & 59 & $2 \cdot 81 \pm 4 \cdot 23$ & 62 & $5 \cdot 60 \pm 4 \cdot 23$ & 68 & $5 \cdot 55 \pm 6 \cdot 14$ \\
\hline Other chromosomal abnormalities & $19+$ & $0 \cdot 85 \pm 1 \cdot 28$ & 25 & $2 \cdot 25 \pm 1 \cdot 95$ & 18 & $1 \cdot 47 \pm 3 \cdot 24$ \\
\hline
\end{tabular}

${ }^{*} \mathrm{p}<0.05, \uparrow \mathrm{p}<0.01$ for differences between Alzheimer patients and healthy controls or Alzheimer patients and 'senescent' controls.

TABLE 2 Results of chromosome studies in male patients with Alzheimer presenile dementia, healthy controls, and 'senescent' controls.

\begin{tabular}{|c|c|c|c|c|c|c|}
\hline & \multicolumn{2}{|c|}{ Healthy controls } & \multicolumn{2}{|c|}{ Alzheimer patients } & \multicolumn{2}{|c|}{ 'Senescent' controls } \\
\hline & No & $\begin{array}{l}\% \\
(M e a n \pm S D)\end{array}$ & No & $\begin{array}{l}\% \\
(\text { Mean } \pm S D)\end{array}$ & No & (Mean $1 S D)$ \\
\hline Total cells & 716 & 100 & 611 & 100 & 600 & 100 \\
\hline $46, N$ & 666 & $93 \cdot 0 \pm 5 \cdot 53$ & 555 & $90 \cdot 8 \pm 5 \cdot 8$ & 543 & $90 \cdot 5 \pm 6 \cdot 00$ \\
\hline $45,-X$ or $Y$ & 9 & $1 \cdot 26 \pm 2 \cdot 06$ & 7 & $1 \cdot 14 \pm 1 \cdot 55$ & 8 & $1 \cdot 33 \pm 1 \cdot 74$ \\
\hline $47,+\mathrm{X}$ or $\mathrm{Y}$ & 1 & 0.14 & 2 & $0 \cdot 33 \pm 1 \cdot 38$ & 1 & $0.16^{-1.17}$ \\
\hline Ace $(X)$ & $1 *$ & $0 \cdot 14$ & $1 \overline{1}$ & $1 \cdot 8 \pm 1 \cdot 8$ & 13 & $2 \cdot 17 \pm 2 \cdot 58$ \\
\hline Other non-modal cells & 27 & $3 \cdot 77 \pm 4 \cdot 15$ & 27 & $4 \cdot 42 \pm 5 \cdot 8$ & 25 & $4 \cdot 17 \pm 3 \cdot 31$ \\
\hline Other chromosomal abnormalities & 12 & $1 \cdot 68 \pm 2 \cdot 58$ & 9 & $1 \cdot 47 \pm 2.06$ & 10 & $1.67 \pm 2.69$ \\
\hline
\end{tabular}

${ }^{*} \mathrm{p}<0.01$ for differences between Alzheimer patients and healthy controls or Alzheimer patients and 'senescent' controls. 
those with an acentric (other than of an $\mathrm{X}$ chromosome), dicentric, or abnormal monocentric chromosome.

Table 1 presents the results of chromosome studies in female subjects. The number of apparently normal cells $(46, N)$ was reduced in the Alzheimer patients $(87 \%)$ when compared to the age matched controls $(93 \%)$, but this reduction was not as marked as that seen in the 'senescent' controls $(83 \%)$. The percentages of abnormal cells differed significantly $(p<0.01)$ between Alzheimer patients and age matched controls. The number of aneuploid cells, missing both sex chromosomes and autosomes, was twice as great in the Alzheimer patients as in the age matched controls, but as the numbers were small the difference was not significant. There was no difference between the Alzheimer patients and the age matched controls for cells with an acentric X chromosome, but 'other chromosomal abnormalities' were more commonly seen $(p<0.01)$ in female Alzheimer patients than age matched controls.

There was also a significant difference $(p<0.05)$ in abnormal cells between Alzheimer patients and 'senescent' controls. The numbers of cells with $45, X$ and acentric $X$ chromosomes were more frequent $(p<0.05)$ in the 'senescent' controls. The $47, \mathrm{XXX}$ cells were much rarer, but nevertheless in the female 'senescent' controls the numbers were almost double those found in the Alzheimer patients, and treble those found in age matched controls, though these differences did not reach formal statistical significance.

The results of the chromosome studies in the males are given in table 2. Again, the highest $\stackrel{\overrightarrow{\mathbb{D}}}{+}$ percentage of normal cells $(46, N)$ was found in the age matched controls $(93 \%)$, while the other two $\stackrel{\text { Of }}{+}$ groups had very similar percentages (about $90 \%$ ). There was no significant difference between the $\frac{\bar{\sigma}}{\overline{0}}$ Alzheimer patients and the control groups, either $\frac{5}{\vec{D}}$ in the number of normal $(46, N)$ or in the various $\stackrel{\mathbb{Q}}{2}$ categories of abnormal cells with the exception of $ळ$ those with an acentric $X$ chromosome. The healthy $\overrightarrow{0}$ controls had significantly $(p<0.01)$ fewer acentric $X:$ cells than either the Alzheimer patients or 'senescent' $\vec{\omega}$ controls.

Because the cells from all Alzheimer patients and $\overline{0}$ controls were analysed fully if they were aneuploid, it was possible to examine not only which cells had? lost a sex chromosome but also which autosome $\vec{P}$ was lost from a cell with 45 chromosomes. Table 3 के gives the numbers of cells which had lost a particular $\stackrel{5}{5}$ autosome. Smaller chromosomes (17 to 22$)$ were $\overrightarrow{7}$ lost more readily than larger ones, but among the $\mathbb{T}$ group of smaller chromosomes no particular chromosome was favoured. It is perhaps surprising, if loss of an autosome is dependent upon size, that chromosomes 13 to 16 were not more readily lost, $\vec{\oplus}$ since they are not much larger than 17 and 18 . If loss is independent of autosome size, then loss of any particular chromosome should be random. Assuming random loss and dividing chromosomes into their Denver Conference ${ }^{21}$ groups, the figure presents the observed and expected numbers of chromosomes $\mathbb{Q}$ lost from each group. Chromosomes from groups $\vec{\Rightarrow}$ $\mathrm{E}, \mathrm{F}$, and $\mathrm{G}$ were most often lost in all three groups $\frac{\overrightarrow{3}}{3}$ of subjects.

TABLE 3 Loss of an autosome from the cells with 45 chromosomes.

\begin{tabular}{|c|c|c|c|c|c|c|c|c|c|}
\hline \multirow[t]{2}{*}{ Chromosome } & \multicolumn{3}{|c|}{ Healthy controls } & \multicolumn{3}{|c|}{ Alzheimer patients } & \multicolumn{3}{|c|}{ 'Senescent' controls } \\
\hline & $F$ & $M$ & Total & $F$ & $M$ & Total & $F$ & $M$ & Total \\
\hline 1 & 0 & 0 & 0 & 0 & 0 & 0 & 0 & 1 & 1 \\
\hline 2 & 0 & 0 & 0 & 0 & 1 & 1 & 2 & 0 & 2 \\
\hline 3 & 1 & 0 & 1 & 2 & 0 & 2 & 2 & 1 & 3 \\
\hline 4 & 3 & 1 & 4 & 2 & 0 & 2 & 2 & 1 & 3 \\
\hline 5 & 0 & 0 & 0 & 0 & 0 & 0 & 1 & 0 & 1 \\
\hline 6 & 1 & 0 & 1 & 1 & 0 & 1 & 0 & 0 & 0 \\
\hline 7 & 0 & 1 & 1 & 2 & 0 & 2 & 2 & 0 & 2 \\
\hline 8 & 1 & 0 & 1 & 2 & 1 & 3 & 5 & 1 & 6 \\
\hline 9 & 1 & 1 & 2 & 0 & 2 & 2 & 4 & 1 & 6 \\
\hline 10 & 1 & 0 & 1 & 3 & 0 & 3 & 2 & 0 & 2 \\
\hline 11 & $i$ & 0 & 1 & 2 & 0 & 2 & 2 & 0 & 2 \\
\hline 12 & 1 & 0 & 1 & 1 & 0 & 1 & 1 & 0 & 1 \\
\hline C & 0 & 1 & 1 & 0 & 0 & 0 & 1 & 0 & 1 \\
\hline 13 & 0 & 0 & 0 & 2 & 0 & 2 & 5 & 1 & 6 \\
\hline 14 & 0 & 1 & 1 & 2 & 0 & 2 & 0 & 1 & 1 \\
\hline 15 & 2 & 0 & 2 & 0 & 0 & 0 & 0 & 0 & 0 \\
\hline 16 & 0 & 2 & 2 & 0 & 0 & 0 & 1 & 0 & 1 \\
\hline 17 & 4 & 4 & 8 & 1 & 0 & 1 & 5 & 3 & 8 \\
\hline 18 & 2 & 1 & 3 & 7 & 1 & 8 & 2 & 2 & 4 \\
\hline 19 & 4 & 3 & 7 & 1 & 4 & 5 & 7 & 3 & 10 \\
\hline 20 & 4 & 1 & 5 & 7 & 0 & 7 & 5 & 1 & 6 \\
\hline 21 & 3 & 2 & 5 & 6 & 2 & 8 & 5 & 0 & 5 \\
\hline 22 & 8 & 0 & 8 & 4 & 1 & 5 & 5 & 4 & 9 \\
\hline Total & 37 & 18 & 55 & 45 & 12 & 57 & 60 & 20 & 80 \\
\hline
\end{tabular}




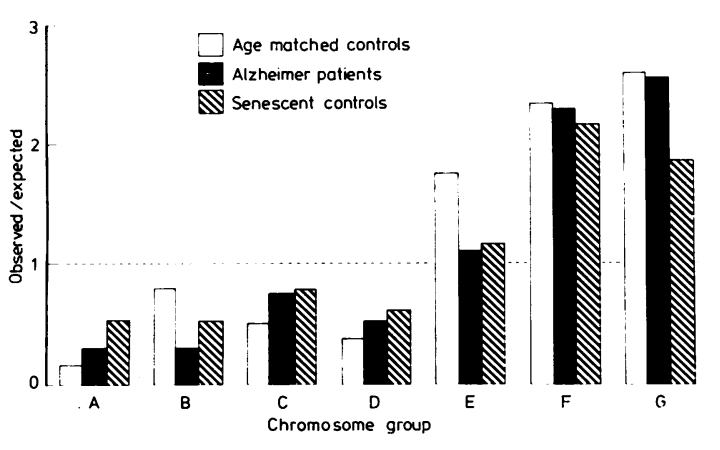

FIGURE Autosomes lost in each Denver group $(A-G)$ in healthy controls, Alzheimer patients, and senescent controls expressed as the observed/expected ratio assuming each chromosome has an equal chance of loss.

The six patients for whom the diagnosis of Alzheimer's disease was confirmed at necropsy were examined separately and did not differ from the remaining patients in terms of the chromosome findings described above.

Two patients were considered in particular detail. The first, a 42-year-old lady, was the only patient with familial Alzheimer's disease, the diagnosis being confirmed at necropsy. Even though she was 10 years younger than any of the other Alzheimer patients, she had extensive chromosome changes in the 50 cells analysed. There were four $45, X$ cells and four cells with an abnormality of one X chromosome, usually involving a rearrangement. The second patient was the only one of our subjects found to have a constitutional chromosome abnormality. The disease had become apparent at the age of 58, she was 65 years old when the blood sample was taken for chromosome studies, and she died the following year when unfortunately permission for necropsy was refused. At chromosome analysis she had two cell lines in her peripheral blood leucocytes. Approximately $50 \%$ of her cells were $46, X X$ and the other half were $47, X X$, + marker. This was a very small additional marker chromosome which did not appear to have a nucleolar organising region and was negative for DA-DAPI stain, indicating that the marker chromosome was not material from the short arm of chromosome $15 .^{22}$

\section{Discussion}

So far there have been seven other studies of chromosome changes in presenile dementia of the Alzheimer type. In only one of these studies ${ }^{18}$ were significant differences detected between patients and controls, when increased aneuploidy was observed. This largely affected sex chromosomes and was particularly evident in familial cases. In a comparable study, Nordensen et $a l^{13}$ found acentric chromosome fragments of varying sizes in 10 patients with Alzheimer's presenile dementia but were unable to comment on the significance of the abnormalities concerned. Failure to detect significant differences in cytogenetic studies of Alzheimer's presenile dementia may have been caused by the small numbers of patients included in these studies (type II error). Though the number of female patients included in the present study was sufficient to avoid this type of error, too few male subjects were included to detect significant differences in abnormalities affecting sex chromosomes. More extensive studies may yet reveal that male patients with Alzheimer's disease do in fact share the chromosome changes seen in female patients.

Particular attention was paid to the possibility that Alzheimer patients had specific chromosomal abnormalities. We were unable to confirm the observations of Bergener and Jungklaass ${ }^{12}$ of abnormal acrocentric chromosomes in Alzheimer's disease, although in female patients there was an increase in cells with other chromosomal aberrations. In our study, these aberrations involved not only deletion of chromosomal material but also reciprocal translocations, inversions, rings, and dicentrics. Furthermore, because there is a strong association between Alzheimer's disease and Down's syndrome ${ }^{6}$ we examined the possibility that chromosome 21 might be specifically affected. Gain of autosomes was very rarely observed in any of the subjects studied, autosomal loss being much more frequent. Cells which had lost one autosome constitute the major group in the column 'other non-modal cells' in tables 1 and 2. In Alzheimer's disease, autosomal loss was more extensive than in healthy matched controls, but not as great as that seen in nondemented senescent controls. Table 3 shows that the pattern of autosomal loss was similar in each of the three groups studied. Chromosome 21 (a G group chromosome) did not appear to be particularly affected in Alzheimer's disease. Smaller chromosomes were lost much more often than larger chromosomes, but chromosomal size alone could not explain all observations in this respect. Chromosome 16, which is grouped in size with chromosomes 17 and 18 (group E), was lost only one-fifth as often as chromosomes 17 or 18 . Since the present study was started, however, more sophisticated cytogenetic methods have become available. High resolution banding techniques might detect small chromosome rearrangements (particularly affecting chromosome 
21) that our methods did not reveal. Further study may yet support the contention that in Alzheimer's disease some cells show excess genetic material from the long arm of chromosome 21 , as is observed as a constitutional abnormality in Down's syndrome.

The study design allowed comparison to be made with both healthy, age matched controls and senescent, non-demented controls. Chromosome changes observed in Alzheimer's disease were similar in nature but not as extensive as those observed in ageing in the absence of dementia. The possibility that chromosome aneuploidy precedes or is an important factor in the onset of Alzheimer's disease is not supported by our observation of more extensive aneuploidy in senescent, nondemented female controls when compared to female Alzheimer patients. If aneuploidy and dementia were initiated by the same process, then more extensive aneuploidy would not be expected to develop in the absence of dementia. These observations suggest that increased chromosome aneuploidy would not be a useful marker for dementia in persons at risk for the disorder, as has been suggested by Cook et al. ${ }^{5}$

Specific pathogens have been associated with the development of both chromosome changes with ageing and Alzheimer's disease. These include the action of environmental agents such as viruses, ${ }^{23} 24$ and the effects of ageing upon cell turnover. ${ }^{25}$ In Alzheimer's disease, impaired trophic hormone secretion may follow specific neurotransmitter deficits observed in the hypothalamus, ${ }^{26}$ and so produce both the neuropathological features of Alzheimer's disease and abnormalities in circulating lymphocytes. ${ }^{9}$

This study represents the most extensive cytogenetic examination so far reported in Alzheimer's presenile dementia. Our observations of chromosomal abnormalities, similar to but not as extensive as those observed in ageing in the absence of dementia, suggest that in some way pathological processes comparable to those of ageing are occurring in Alzheimer's disease. Future studies of Alzheimer's disease might usefully include other measures of ageing and so define the possible contribution of ageing processes to the pathogenesis of Alzheimer's dementia.

The authors wish to thank the staff and volunteers from the Edinburgh and Leith Old People's Welfare Association at Lamb's House. We are also grateful to Drs W J Price and M Newton for their assistance in this study, and to Mrs M Dodd for preparation of the manuscript.

\section{References}

1 Editorial. Alzheimer's disease. Br Med J 1980;281:1374.

2 Editorial. Organic mental impairment in old people. Lancet 1981 ;ii:561-2.

3 Editorial. Amyloidosis of Alzheimer's disease: a clue to ageing? Lancet $1970 ;$ ii:598-9.

4 Comfort A. The biology of senescence. Edinburgh: Churchill Livingstone, 1979:153-76.

5 Cook RH, Ward BE, Austin YH. Studies in aging of the brain. IV. Familial Alzheimer disease: relation to transmissible dementia, aneuploidy and microtubular defects. Neurology 1979;29:1402-12.

6 Olson MJ, Shaw CM. Presenile dementia and Alzheimer's disease in Mongolism. Brain 1969;92:147-56.

7 Jacobs PA, Court Brown WM, Doll R. Distribution of human counts in relation to age. Nature 1960;191:117880.

8 Jacobs PA, Brunton M, Court Brown WM, Doll R, Goldstein, H. Change of human chromosome count distributions with age: evidence for a sex difference. Nature 1963;197:1080-1.

9 Court Brown WM, Buckton KE, Jacobs PA, Tough IM, Kuenssberg E, Knox JDE. Chromosome studies on adults. Eugenics Laboratory Memoirs No 42. Cambridge: Cambridge University Press, 1966.

10 Galloway SM, Buckton KE. Aneuploidy and ageing: chromosome studies on a random sample of the population using G-banding. Cytogenet Cell Genet 1978;20: 78-95.

11 Nielsen $\mathbf{J}$. Chromosomes in senile, presenile and arteriosclerotic dementia. J Gerontol 1970;25:312-5.

12 Bergener M, Jungklaass FK. Genetische Befunde bei Morbus Alzheimer und seniler Demenz. Gerontology 1970;12:71-5.

13 Nordensen I, Adolfsson R, Beckman G, Bucht G, Winblad B. Chromosomal abnormality in dementia of Alzheimer type. Lancet 1980;i:481-2.

14 Jarvik LF, Altschuler KZ, Kato T, Blummer B. Organic brain syndrome and chromosome loss in aged twins. Dis Nerv Syst 1971;32:159-70.

15 Jarvik LF, Yen FS, Goldstein F. Chromosomes and mental status. Arch Gen Psychiatry 1974;30:186-90.

16 Mark J, Brun A. Chromosomal deviations in Alzheimer's disease compared to those in senescence and senile dementia. Gerontology 1973;15:253-8.

17 Brun A, Gustafson L, Mitelman F. Normal chromosome banding pattern in Alzheimer's disease. Gerontology $1978 ; 24: 369-72$.

18 Ward BE, Cook RH, Robinson A, Austin JH. Increased aneuploidy in Alzheimer disease. Am J Med Genet 1979 ; 3:137-44.

19 Martin JM, Kellett JM, Kahn J. Aneuploidy in cultured human lymphocytes. II. A comparison between senescence and dementia. Age Ageing 1981;10:24-8.

20 White BJ, Crandall C, Goudsmit J, et al. Cytogenetic studies of familial and sporadic Alzheimer disease. Am J Med Genet $1981 ; 10: 77-89$.

21 Denver Conference. A proposed standard system of nomenclature of human mitotic chromosomes. Lancet $1960 ; \mathbf{i}: 1063-5$.

22 Spowart G. Reassessment of presumed $Y / 22$ and $Y / 15$ translocation in man using a new technique. Cytogenet Cell Genet 1979;23:90-4.

23 Harnden DG. Viruses, chromosomes and tumours: interaction between viruses and chromosomes. In: German J, ed. Chromosomes and cancer. New York: Wiley, 1974: 151-90. 
24 Wisniewski HM. Possible viral etiology of neurofibrillary changes and neurotic plaques. In: Katzmann R,Terry RD, Bick KL, eds. Alzheimer's disease: senile dementia and related disorders. Ageing. Vol 7. New York: Raven Press, 1978:555-7.

25 Fishman HK, Albu P, Reisberg B, Ferris S, Rainer JD. Cell cycle kinetics and chromosome alterations in Alzheimer disease (abst). 6th International Congress of Human Genetics, Israel, 1981.
26 Yates CM, Ritchie IM, Simpson J, Maloney AFJ, Gordon A. Noradrenaline in Alzheimer-type dementia and Down syndrome. Lancet 1981 ;ii:39-40.

Requests for reprints to Dr K E Buckton, MRC Clinical and Population Cytogenetics Unit, Western General Hospital, Crewe Road, Edinburgh, EH4 2XU. 